\title{
Stenosis of pulmonary veins with ventricular septal defect
}

\section{A cause of premature pulmonary hypertension in infancy}

\author{
PATRIZIA PRESBITERO, CATHERINE BULL, FERGUS J MACARTNEY
}

From The Hospital for Sick Children, Great Ormond Street, London

SUMMARY Two infants with pulmonary hypertension resulting from unilateral pulmonary vein stenosis and ventricular septal defect are reported. Treatment implies the closure of the ventricular 8 septal defect which contributes per se to the development of pulmonary hypertension, but relief of $\frac{0}{2}$ the pulmonary vein obstruction is not always feasible, and postoperative problems may result.

Pulmonary vein stenosis is recognised as a rare, silent cause of pulmonary hypertension. ${ }^{1}$ The condition can occur with or without intracardiac anomalies. ${ }^{1-3}$ The presence of lesions, such as ventricular septal defect, which cause pulmonary hypertension in their own right, can make suspicion of associated pulmonary venous obstruction difficult. In only one of the four reported cases $^{4-7}$ of ventricular septal defect with pulmonary vein stenosis was the diagnosis made before operation. We report two further cases with unusual clinical presentation.

\section{Case reports}

CASE 1

This male infant was admitted to The Hospital for Sick Children, London, at the age of 2 months. A murmur had been heard in the first week of life. Because of mild cyanosis on crying and four episodes of extreme pallor, the child was referred with the clinical diagnosis of Fallot's tetralogy.

Clinically he was pink, with an ejection click, a systolic ejection murmur in the pulmonary area, a single second heart sound, and no diastolic murmur. The chest $x$-ray film showed a normal heart with a slightly small, hypovascular lung on the right. Two dimensional echocardiogram showed only a large perimembranous infundibular ventricular septal defect.

Cardiac catheterisation was performed. The pulmonary artery pressure was raised at systemic level. The wedge pressures showed important differences

FJM is supported by the British Heart Foundation and Vandervell Foundation. Accepted for publication 15 February 1983 between the two lungs: $a=24 \mathrm{mmHg}, y=20 \mathrm{mmHg}$, mean $23 \mathrm{mmHg}$ in the right lung, and $a=10 \mathrm{mmHg}, \vec{\oplus}$ $y=8 \mathrm{mmHg}$, mean $6 \mathrm{mmHg}$ in the left lung. The mean left atrial pressure measured directly was 40 $\mathrm{mmHg}$; the left pulmonary veins were entered and no gradient between these and the left atrium was detected. The right pulmonary veins could not be® intubated. A large left to right shunt was documented partly at atrial and partly at ventricular level with an element of right to left shunt mainly at atrial level, giving an aortic saturation of $85 \%$. The calculated pulmonary vascular resistance was $2 \cdot 2$ units $/ \mathrm{m}^{2}$.

The left ventricular angiocardiogram showed a single, high ventricular septal defect below the infun- $-\bar{\Phi}$ dibular septum. The pulmonary angiocardiogram? showed severe obstruction to flow through the right lung. The venous return from the left lung was nor$\mathrm{mal}$ and the site of return from the right lung waso never well visualised (Fig. 1).

\section{Surgical findings}

An atrial septal defect and a large perimembranous infundibular ventricular septal defect were found and closed. The right pulmonary veins were very hypoplastic and connected to the left atrium through aO single minute orifice. Nothing could be done tow relieve the obstruction because of the diffuse hypoplasia of the extrapulmonary veins. At the end of theo procedure the pulmonary artery pressure was 450 mmHg with a systemic arterial pressure of $70 \mathrm{mmHg}$ ? The child had a stormy postoperative course including episodes of "blue spells" when agitated which웅 were attributed to pulmonary hypertensive crises. ${ }^{8}$

Four months after operation he is doing well, and is acyanotic with an unimpressive systolic murmuro and an ejection click. 

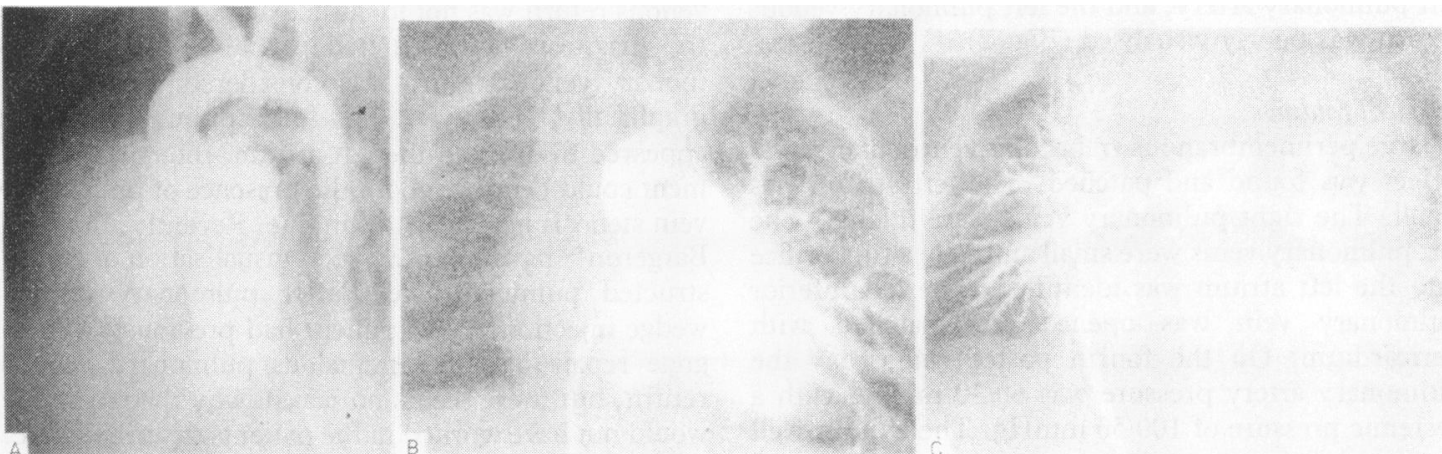

Fig. 1 Case $1(A)$ Left ventricular angiogram: position and size of the ventricular septal defect. (B) Right ventricular angiogram: early opacification of the main and left pulmonary artery with its branches while the right pulmonary tree is not opacified. $(C)$ Pulmonary angiogram, late frame: prompt venous retum from the left lung, while the right pulmonary angiogram is still in the arterial phase.
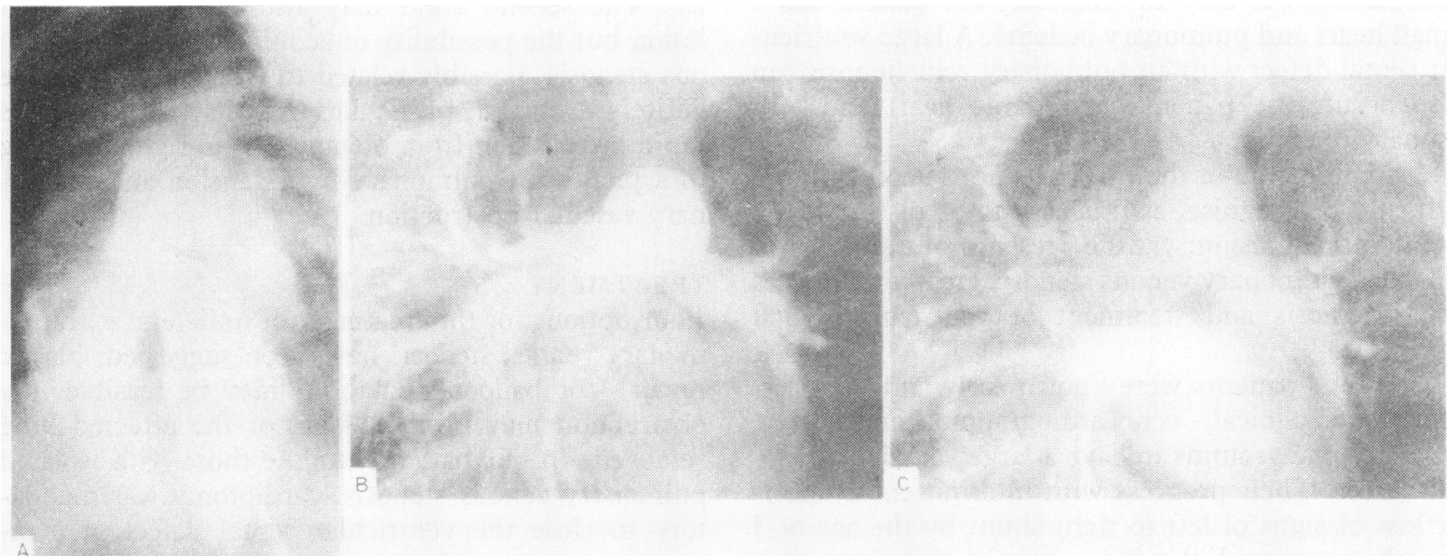

Fig. 2 Case $2(A)$ Left ventricular angiogram: position and size of the ventricular septal defect. (B) Right ventricular angiogram early frame: late and faint opacification of the branches of the left pulmonary artery. (C) Late frame: normal venous return from the right lung; the venous return from the left lung is not well identified.

\section{CASE 2}

This child was first seen at 20 days of age with breathlessness on feeding. There was a pansystolic murmur at the left sternal border, a fixed split second sound, and an apical diastolic rumble. The chest $x$-ray film showed an enlarged heart with pulmonary plethora but no detectable difference between the two lungs. The two dimensional echocardiogram showed a perimembranous trabecular ventricular septal defect of moderate size. Two months later the systolic murmur was softer and the diastolic rumble had disappeared. Over the next three months two episodes of infection involving both lungs required treatment in hospital. By 7 months of age the child had clinical signs of pulmonary hypertension with diminished shunt.
Cardiac catheterisation was immediately performed and confirmed the clinical impression of pulmonary hypertension. The pressure in the pulmonary artery was raised to systemic level and the mean wedge pressures were $30 \mathrm{mmHg}$ in the left and $16 \mathrm{mmHg}$ in the right pulmonary artery. Only the right pulmonary veins were entered and a pressure of $16 \mathrm{mmHg}$ was recorded. The left atrial and left ventricular enddiastolic pressures were $10 \mathrm{mmHg}$. The saturation data showed a shunt of $2 \cdot 2: 1$ at ventricular level, again with a small right to left shunt at atrial level, giving an aortic saturation of $90 \%$. The calculated pulmonary resistance was 5.3 units $/ \mathrm{m}^{2}$. The left ventricular angiocardiogram showed a ventricular septal defect of moderate size. The right ventricular angiocardiogram showed very poor filling of the distal branches of the 
left pulmonary artery, and the left pulmonary venous return was poorly visualised (Fig. 2).

\section{Surgical findings}

A large perimembranous trabecular ventricular septal defect was found and patched. The left atrium was small. The right pulmonary veins were dilated. The left pulmonary veins were small and only a tiny orifice into the left atrium was identified. The left inferior pulmonary vein was opened and patched with pericardium. On the fourth postoperative day the pulmonary artery pressure was $60 / 30 \mathrm{mmHg}$ with a systemic pressure of $100 / 50 \mathrm{mmHg}$. The child is well six months after operation.

\section{Discussion}

Pulmonary venous obstruction without intracardiac shunt (the pulmonary veins commonly draining anomalously) is easy to diagnose; the patient has a small heart and pulmonary oedema. A large ventricular septal defect without pulmonary vein stenosis can also occur; the patient has a large heart and pulmonary plethora.

A combination of the two conditions is much more difficult to recognise, as it is easy to be distracted by the dominant lesion; yet the presence of unilateral or bilateral pulmonary venous stenosis greatly influences the prognosis and treatment of ventricular septal defect.

Both our patients were known early and with certainty on clinical, echocardiographic, and, later, angiographic grounds to have a large ventricular septal defect. Their progress with intermittent cyanosis or loss of signs of left to right shunt by the age of 3 months suggested the premature evolution of pulmonary vascular obstructive disease. Though this can very occasionally occur in isolated ventricular septal defect, it must raise the suspicion of an associated anomaly. ${ }^{9}$

\section{DIAGNOSIS}

The key to the diagnosis of pulmonary venous obstruction is the documentation of a discrepancy between pulmonary wedge pressure and left atrial pressure measured directly. In both our cases this discrepancy was highlighted by the contrast between wedge recordings from the normally draining and obstructed lungs. Collaborative evidence comes from failure to enter the obstructed veins from the left atrium. Thirdly, a right sided angiocardiogram shows delayed pulmonary venous return to the heart, again the dissimilarity between flow patterns through the two lungs underlining the diagnosis in our patients. In fact, in both patients, flow through the affected pulmonary veins was so low that the site of pulmonary venous return was not identified angiographically and $c$ the diagnosis of obstructed partial anomalous pul- $\overrightarrow{\vec{F}}$ monary venous return was considered. Echocardiographically, however, all four pulmonary veins appeared to drain to the left atrium, though no com- $\frac{\bar{c}}{\bar{c}}$ ment could be made about the presence of pulmonary vein stenosis using this technique. Recently, Bini and $\unrhd$ Bargeron ${ }^{10}$ have reported good visualisation of an ob- $₫$ structed pulmonary vein after pulmonary arterial $\vec{\circ}$ wedge injection. Their patient had previously undergone repair of total anomalous pulmonary venous $\vec{\omega}$ return, but there seems no reason why the technique would not have worked in the patients described here.

\section{AETIOLOGY}

Pulmonary venous obstruction may be congenital or acquired. ${ }^{21112}$ In our first patient, a congenital lesion seems likely as the patient was mildly cyanotic at pre- $\triangle$ sentation and the lung on the affected side was smal- $\vec{c}$ ler. The second child may also have a congenital lesion but the possibility of acquired pulmonary ven- $\Phi$ ous stenosis, possibly related to infection, cannot be $\vec{\varphi}$ entirely excluded, particularly in view of the child's $\stackrel{\infty}{\infty}$ rapid progression from obvious left to right shunting to a picture of pulmonary hypertension and pulmonary vascular obstruction.

\section{TREATMENT}

Four options for the treatment of unilateral extrapul- $\frac{\varrho}{\not}$ monary venous stenosis have been suggested: plastic $\stackrel{\circ}{ }$ repair ${ }^{13}$ or balloon dilatation ${ }^{7}$ may be feasible, the $\frac{}{5}$ obstruction may be left alone, or the affected lung removed. In our patients, unlike those with isolated pulmonary venous stenosis, cardiotomy was mandatory to close the ventricular septal defect, a man- $\frac{\Re}{7}$ oeuvre that would be expected, on its own, to ameliorate the pulmonary hypertension. The success? of the angioplasty in relieving the stenosis of one pul- 0 monary vein in one of our infants is not known, but $₹$ the other affected veins were too diffusely hypoplastic음 for repair even to be attempted. Moreover, under $>$ direct vision, it was clear that any attempt at balloon응. dilatation would have failed because of extremen hypoplasia of the pulmonary vein orifice. Thus, in our patients, at least some pulmonary segments were left 0 with unrelieved venous hypertension. Sade et al. ${ }^{3} \mathrm{C}$ argue that such segments should be removedimplying pneumonectomy in our patients-pointingo out that detrimental medial muscular hypertrophy of the pulmonary arteries occurs bilaterally, even when ${ }^{\text {? }}$ venous stenosis is unilateral. Both our patients were? left with raised pulmonary artery pressure after clos- $\frac{0}{8}$ ure of the ventricular spetal defect and behaved post- $\Omega$ operatively in a way suggesting an important element $\mathbb{Q}_{2}$ of residual, labile pulmonary hypertension, presum- $-\overline{2}$ ably related to bilateral muscular arteriolar hypertro- 
phy. Both will require follow up catheterisation to reassess their haemodynamics in the absence of a shunt and the question of pneumonectomy may be considered. The outcome of pneumonectomy in infancy is so poor that the precedure was not contemplated at initial operation.

\section{References}

1 Binet JP, Bouchard F, Langlios J, Chetochine F, Conso JF, Pottemain M. Unilateral congenital stenosis of the pulmonary veins. $\mathcal{F}$ Thorac Cardiovasc Surg 1972; 63: 397-402.

2 Shone JD, Amplatz K, Anderson RC, Adams P Jr, Edwards JE. Congenital stenosis of individual pulmonary veins. Circulation 1962; 26: 574-81.

3 Sade RM, Freed MD, Matthews EC, Castaneda AR. Stenosis of individual pulmonary veins. Review of the literature and report of a surgical case. $\mathcal{F}$ Thorac Cardiovasc Surg 1974; 67: 953-62.

4 Park SC, Neches WH, Lenox CC, Zuberbuhler JR, Siewers RW, Bahnson HT. Successful preoperative diagnosis and surgical repair of pulmonary vein stenosis [Abstract]. Circulation 1973; 47- 48 (suppl IV): 33.

5 Kawashima Y, Veda T, Naito Y, Morikawa E, Manabe $\mathrm{H}$. Stenosis of pulmonary veins. Report of a patient corrected surgically. Ann Thorac Surg 1971; 12: 196-202.
6 Kinoshite T, Yamazaki Y, Kusakawa M, Aoki K, Yoshizumi K. Extrapulmonary vein stenosis associated with ventricular septal defect [Abstract]. $\mathcal{f p}_{p}$ Circ $\mathcal{F}$ 1975; 39: 874.

7 Driscoll DJ, Hesslein PS, Mullins CE. Congenital stenosis of individual pulmonary veins: clinical spectrum and unsuccessful treatment by transvenous balloon dilation. Am f Cardiol 1982; 49: 1767-72.

8 Jones ODH, Shore DF, Rigby ML, et al. The use of Tolazoline Hydrochloride as a pulmonary vasodilator in potentially fatal episodes of pulmonary vasoconstriction after cardiac surgery in children. Circulation 1981; 63-64 (suppl II): 134-9.

9 Moss AJ, Adams FH, Emmanouilides GC, eds. Heart disease in infants, children and adolescents. 2nd ed. Baltimore: Williams and Wilkins, 1977: 631.

10 Bini RM, Bargeron LM. Visualization of pulmonary vein obstruction by pulmonary artery wedge injection. Pediatr Cardiol 1982; 2: 161-2.

11 Heath D, Segel N, Bishop J. Pulmonary veno-occlusive disease. Circulation 1966; 34: 242-8.

12 Massumi A, Woods L, Mullins CE, Nasser WK, Hall RJ. Pulmonary venous dilatation in pulmonary venoocclusive disease. Am F Cardiol 1981; 48: 585-9.

Requests for reprints to Professor F J Macartney, The Hospital for Sick Children, Great Ormond Street, London WC1N 3JH. 